\title{
REPRESENTAÇÕES SOCIAIS DAS DST/AIDS ELABORADAS POR GESTANTES
}

\author{
Dayse Olivia Damasceno ${ }^{1}$, Fernanda Maria de Jesus Sousa Pires Moura², Inez Sampaio Nery³, Odinéa Maria \\ Amorim Batista ${ }^{4}$, Olívia Dias de Araújo ${ }^{5}$, Lara de Jesus Sousa Pires de Moura ${ }^{6}$
}

\footnotetext{
${ }^{1}$ Enfermeira. Professora da Escola São Camilo e Enfermeira da Casa de Custódia de Teresina. Piauí, Brasil. E-mail: dayseolivi@ bol.com.br

${ }^{2}$ Mestre em Enfermagem. Professora do Departamento de Enfermagem da Universidade Federal do Piauí (UFPI). Piauí, Brasil. E-mail: fernandasousav@bol.com.br

${ }^{3}$ Doutora em Enfermagem. Professor Adjunto do Departamento de Enfermagem da UFPI. Piauí, Brasil. E-mail: nery@webone. com.br

${ }^{4}$ Mestre em Enfermagem. Professora da Associação de Ensino Superior e Tecnologia do Piauí. Piauí, Brasil. E-mail: obatista@ novafapi.com.br

${ }^{5}$ Mestranda em Enfermagem. Enfermeira do Programa Saúde da Família de Teresina. Piauí, Brasil. E-mail: olíviaenf@ig.com.br

${ }^{6}$ Enfermeira. Piauí, Brasil. E-mail: lara.pires.21@hotmail.com
}

RESUMO: Estudo exploratório qualitativo com a utilização da Teoria das Representações Sociais que objetivou apreender e discutir as representações sociais sobre as Doenças sexualmente transmissíveis e a Síndrome da imunodeficiência adquirida formuladas por 40 gestantes que realizavam pré-natal no Bairro Satélite de Teresina-PI. O instrumento utilizado para coleta de dados foi o Teste de Associação Livre de Palavras e foram processados no software Tri-Deux Mots e interpretados por meio da análise fatorial de correspondência. Os resultados mostraram que o campo representacional dos sujeitos está constituído pelas evocações: coceira, corrimento, dor, insegurança, medo, prevenção, perigo e camisinha, ancoradas no aspecto sociocultural e psicológico. Assim, as representações sociais foram expressas pelas mulheres com o aspecto social, cultural e psicológico sobre a prevenção e o controle das doenças sexualmente transmissíveis e a síndrome da imunodeficiência adquirida.

DESCRITORES: Doença sexualmente transmissível. Gestantes. Pesquisa qualitativa. Síndrome da imunodeficiência adquirida.

\section{PREGNANT WOMEN'S SOCIAL REPRESENTATIONS OF STD/AIDS}

\begin{abstract}
The aim of this qualitative exploratory study using the Theory of Social Representations was to capture and discuss the social representations about Sexually Transmitted Diseases and Acquired Imunodeficiency Syndrome made by forty pregnant women who received prenatal care in the Satellite District of Teresina-PI, Brazil. The instrument used for data collection was the Test of Free Association of Words. The results were processed in the software Tri-Deux Mots and interpreted through correspondence factorial analysis. The results showed that the representational field of the subjects is constituted by the following evocations: itching, runniness, pain, insecurity, fear, prevention, danger, and condoms, anchored in the socio-cultural and psychological aspects. Thus, social representations have been expressed by women with the social, cultural, and psychological aspects on the prevention and control of sexually transmitted diseases and acquired immunodeficiency syndrome.
\end{abstract}

DESCRIPTORS: Sexually transmitted diseases. Pregnant women. Qualitative research. Acquired immunodeficiency syndrome.

\section{LA REPRESENTACIÓN SOCIAL DE LAS ETS/SIDA PRODUCIDAS POR GESTANTES}

RESUMEN: Estudio exploratorio cualitativo basado en la Teoría de las Representaciones Sociales, cuyo objetivo fue aprehender y discutir las representaciones sociales acerca de las enfermedades transmitidas sexualmente y el síndrome de inmunodeficiencia adquirida. El estudio fue realizado con 40 mujeres embarazadas que hicieron el prenatal en el Barrio Satélite de Teresina-PI. Para la recolección de los datos se empleó la prueba de la Libre Asociación de Palabras, y para su procesamiento se usó el programa Tri-Deux Mots. Los datos fueron interpretados a través del análisis factorial de correspondencia. Los resultados mostraron que el ámbito de la representación de los sujetos está constituido por las siguientes evocaciones: picazón, flujo, dolor, inseguridad, miedo, prevención, peligro y condón, las cuales están arraigadas en el aspecto sociocultural y psicológico. De esa forma, las representaciones sociales manifestadas por las mujeres están relacionadas con el aspecto social, cultural y psicológico en lo que se refiere a la prevención y control de enfermedades de transmisión sexual y el síndrome de inmunodeficiencia adquirida.

DESCRIPTORES: Enfermedades de transmisión sexual. Mujeres embarazadas. Investigación cualitativa. Síndrome de inmunodeficiencia adquirida. 


\section{CONSIDERAÇÕES INICIAIS}

As Doenças Sexualmente Transmitidas (DSTs) são doenças infecciosas que podem ser disseminadas através do contato sexual. Algumas podem também ser transmitidas por vias não sexuais, porém as formas não-sexuais de transmissão são menos freqüentes. Estão entre as cinco principais causas de procura dos serviços de saúde e podem provocar sérias complicações, tais como infertilidade, abortamento espontâneo, malformações congênitas e até a morte, se não tratadas. ${ }^{1}$ Além disso, aumentam a chance, em pelo menos dez vezes, de contaminação pelo Human Immunodeficiency Virus (HIV). São doenças de difícil detecção, uma vez que acarretam poucos sintomas visíveis e, muitas vezes, apresentam-se de forma assintomática. ${ }^{2}$

O período compreendido entre 1981 e 1984 corresponde aos primeiros contatos com a "nova entidade clínica", que veio chamar a atenção dos serviços de saúde, principalmente dos centros de investigação epidemiológica, como o Center for Disease Control (CDC), buscando-se de imediato os fatores de risco associados e traçando-se um perfil epidemiológico e clínico. Sendo, então, detectado um estado de fragilidade no sistema imunológico dos doentes, começou a se difundir o termo Síndrome da Imunodeficiência Adquirida (SIDA), que se tornou mundialmente conhecida pela sua sigla em inglês, AIDS (Acquired Immunodeficiency Syndrome). ${ }^{3}$

O surgimento de casos entre receptores de sangue, hemoderivados e em usuários de drogas injetáveis levou os pesquisadores a procurarem por um agente infeccioso. Como havia uma incidência quase exclusiva entre os gays, promoveram-se buscas por uma ligação entre a homossexualidade e a Aids. Havia então um fator de risco associado a grupos aparentemente delimitados. ${ }^{4}$

Utilizou-se o termo grupo de risco, tendo em vista que a incidência de Aids aparentemente atingia grupos específicos como homossexuais masculinos, hemofílicos e usuários de drogas intravenosas. Essa idéia só veio a ser repensada após o isolamento do HIV em 1983 quando, então, surgiram evidências de que a epidemia não se limitava a grupos ou a regiões, estabelecendo o caráter transmissível da doença. ${ }^{5}$

Em anos recentes, ocorreram no Brasil uma “pauperização" e "feminização" dos casos de infecção pelo HIV. Duas possíveis explicações seria a redução da transmissão sangüínea e sexual homossexual decorrente das primeiras estratégias de prevenção e a postergação e o início das cam- panhas e ações preventivas visando ao público heterossexual, inclusive feminino. ${ }^{6}$

Nesse contexto, se faz necessário o acompanhamento de gestantes através do pré-natal que tem como objetivo acolher a mulher desde o início da gravidez, identificando, prevenindo e tratando doenças, dentre elas, as DSTs/Aids.

No SISPRENATAL está definido o elenco mínimo de procedimentos para uma assistência pré-natal adequada. O que propicia o acompanhamento das gestantes, desde o início da gravidez até a consulta de puerpério.

Assim, reconhecendo a necessidade de estabelecer nova estratégia, em junho de 2000, o Ministério da Saúde instituiu o Programa de Humanização no Pré-Natal e Nascimento (PHPN), que apresenta em sua formulação os seguintes objetivos: reduzir as altas taxas de morbimortalidade materna e perinatal, ampliar o acesso ao Pré-Natal, estabelecer critérios para qualificar as consultas e promover o vínculo entre a assistência ambulatorial e o parto. ${ }^{7}$

De acordo com o programa de humanização no pré-natal para um adequado acompanhamento e assistência à puérpera, é critério fundamental a solicitação dos seguintes exames: grupo sanguíneo e fator RH; sorologia para sífilis (Venereal Disease Research Laboratory -VDLR); urina tipo I; hemoglobina e hematócrito; glicemia de jejum; teste anti-HIV; IgM para toxoplasmose; sorologia para hepatite B e colpocitologia oncótica. Através desses exames é que será detectada a incidência ou não de patologias como as DSTs/Aids.

Diante da problemática exposta, foi utilizada a Teoria das Representações Sociais (TRS) para apreensão das Representações Sociais (RSs) das DSTs/Aids elaboradas por gestantes no contexto da realidade em que estão inseridas. A TRS permite conhecer as construções elaboradas a partir da realidade comum a um grupo social. ${ }^{8}$

Neste contexto, existe uma dificuldade em se definir RSs, por essas designarem um grande número de fenômenos e, dessa forma, estarem presentes em vários campos da ciência, como na Sociologia, na Antropologia e na Psicologia. O que unifica a definição é o fato de que a representação é uma representação de alguma coisa ou de alguém, para isso, utilizando-se da idéia do símbolo. ${ }^{9}$

Através dessa atividade de representar, o indivíduo constrói uma nova realidade de seu mundo, dando-lhe novos significados que o conduzem. Essa interpretação da realidade é traduzida como 
um conjunto lógico de pensamento que vai constituir a visão de mundo para certa coletividade. ${ }^{10}$

As RSs como fenômeno são formas de saber, geradas a partir do conhecimento do senso comum, considerando o sujeito como parte de um conjunto indissociável com objeto e sociedade. A partir dessa perspectiva, busca-se compreender processos que ocorrem em contextos históricos e sócio-culturais precisos, na construção do senso comum. ${ }^{11}$

Dessa forma, a TRS permitiu entender as RSs das DSTs / Aids, enquanto conhecimento elaborado pelas gestantes em consonância com a realidade em que estão inseridas.

Portanto as DSTs constituem um problema de saúde pública relevante porque devido à incidência, o problema é agravado pela grande quantidade de indivíduos que se automedica com tratamentos inadequados, resultando em aumento da resistência antimicrobiana e podendo levar a quadros subclínicos que os mantêm transmissores. Outro aspecto relacionado à alta prevalência das DSTs é que freqüentemente as orientações dadas aos pacientes não contemplam atitudes capazes de prevenir a reincidência da doença e o tratamento dos parceiros, acredita-se que os profissionais desconhecem os aspectos subjetivos que permeiam o fenômeno em estudo.

Diante destas reflexões o estudo tem como objeto as RSs das DSTs/Aids elaboradas por gestantes que realizam o pré-natal.

Para nortear o objeto de estudo desta pesquisa, foi levantado o seguinte questionamento - Quais as Representações Sociais de DST/Aids, elaboradas por gestantes que realizam pré-natal no Bairro Satélite de Teresina-PI?

E com o propósito de responder a esses questionamentos foram elaborados os seguintes objetivos: apreender as RSs das DSTs/Aids formuladas por gestantes que realizam pré-natal no Bairro Satélite, Teresina-PI; e discutir as RSs das DSTs/Aids elaboradas por gestantes atendidas no pré-natal.

Neste contexto, o HIV é o vírus causador da Aids, e sua transmissão ocorre principalmente das seguintes formas: transmissão sexual por meio do contato homossexual, heterossexual ou bissexual; transmissão sangüínea por exposições parenterais ou de mucosas a sangue e hemoderivados; transmissão vertical, que é a principal via de infecção pelo HIV em crianças, ocorrendo no período intra-uterino, trabalho de parto, parto e aleitamento materno de mulheres infectadas; e transmissão ocupacional que se dá quando um profissional de saúde sofre ferimentos por perfuro cortantes contaminados com sangue de clientes infectados pelo HIV. ${ }^{12}$

A sífilis em gestantes, sífilis congênita, a Aids e a infecção pelo HIV em gestantes e crianças expostas são doenças de transmissão sexual de notificação compulsória. Para as outras DSTs, recomenda-se notificação universal baseada em síndromes, via o Sistema de Informação de Agravos de Notificação que aumenta a sensibilidade e a agilidade do sistema. ${ }^{3}$

O conceito de RSs utilizado neste estudo por introduzir a TRS através da Psicologia Social, é um conjunto de conceitos e explicações originadas no cotidiano, dentro das comunicações interpessoais podendo, ser equivalente aos mitos e crenças das sociedades tradicionais, ou ainda uma versão contemporânea do senso comum. ${ }^{13}$

A utilização deste conceito permitiu que as representações identificadas nesta pesquisa através das palavras evocadas, revelassem a realidade, para então, através da compreensão e análise do objeto em estudo, identificar as RSs das gestantes sobre DTS/Aids.

\section{METODOLOGIA}

A presente pesquisa caracteriza-se como um estudo exploratório qualitativo com a utilização da TRS para embasamento dos resultados, por ser adequada para investigar a problemática apresentada, a fim de apreender e discutir as RSs das DSTs/ Aids elaboradas por gestantes. A abordagem qualitativa é adequada para esta investigação, tendo em vista que possibilita uma maior aproximação com o mundo dos significados, das ações permitindo captar o universo de valores, motivações e atitudes que compõem um aspecto não perceptível em equações, médias e estatísticas. ${ }^{14}$

Estudo exploratório tem como principal finalidade desenvolver, esclarecer e modificar conceitos e idéias, tendo em vista, a formulação de problemas mais precisos ou hipóteses pesquisáveis para estudos posteriores. ${ }^{15}$

O cenário da pesquisa foi o bairro satélite, localizado na zona leste em Teresina, onde funcionam três equipes do Programa Saúde da Família. Os sujeitos do estudo foram gestantes residentes no referido bairro, acompanhadas no pré-natal pela equipe 101 do Programa Saúde da Família que atende num Hospital do Bairro Satélite no período da tarde. Escolhemos o Bairro Satélite por ter muitos casos de DSTs em gestantes que freqüentam o serviço de saúde. 
Após o levantamento do número de gestantes com o agente de saúde, foi realizada visita domiciliar a 40 gestantes, que após aceitação verbal assinaram o Termo de Consentimento Livre Esclarecido, com garantia de sigilo das participantes no processo de produção dos dados e divulgação de suas informações como fonte de dados para discussão dos objetivos propostos, levando em consideração o aspecto ético conforme a resolução $\mathrm{N}^{\circ}$ 196/96 do Conselho Nacional de Saúde em Pesquisa com seres Humanos. O projeto de pesquisa foi aprovado no Comitê de Ética em Pesquisa da NOVAFAPI sob No 46/2006.

A coleta de dados da pesquisa realizou-se nos meses de agosto e setembro de 2007. O instrumento de coleta de dados foi composto por duas partes, uma referente à caracterização dos sujeitos, onde foram consideradas três variáveis: idade, escolaridade e estado civil. E a outra parte através do teste de associação livre de palavras, que foi construída por dois estímulos indutores: DST e DST/Aids com associação de seis palavras para cada estímulo proposto que viessem à mente das gestantes.

Antes da aplicação, ilustrou-se com um exemplo semelhante ao que foi utilizado na pesquisa, para familiarizar o entrevistado sobre o procedimento para aplicação do teste e adequação de respostas. As gestantes foram orientadas em relação ao tempo, posto que, quanto mais ágil e impulsiva for à resposta, maior seu efeito de validade. ${ }^{9}$

O teste de associação livre de palavras é um tipo de investigação aberta referente à evocação das respostas dadas a partir de um ou vários estímulos indutores, o que evidencia os universos semânticos das palavras agrupadas em determinadas populações. ${ }^{9,16}$

A primeira parte para codificação dos dados consistiu-se em preparar os dicionários de vocábulos adjetivos apropriados a cada estímulo, em que o estímulo indutor foi agrupado em cada arquivo (dicionário) que conteve todas as respostas colhidas na amostra com relação ao próprio estímulo. A etapa seguinte disponibilizou as respostas em ordem alfabética, em que analisou e identificou quais foram as mais freqüentes, reagrupando-as por similaridade semântica, organizando-as em banco de dados constituídos pelas variáveis de opinião codificadas e agregada a numerais referentes a cada estímulo indutor (1- DST, 2- DST/ Aids) e pelas variáveis fixas (idade, estado civil, escolaridade), expostas nas três primeiras colunas do banco de dados, codificadas desta forma.

Uma vez organizados os dicionários e o banco de dados, os resultados do teste de asso- ciação livre de palavras foram processados no sofware Tri-Deux Mots (versão 2.2), indicadopara tratamento de questões abertas e fechadas e interpretados por meio de Análise Fatorial de Correspondência (AFC). Esse software possibilita averiguar correlações entre grupos, bem como visualizar as relações de atração e afastamento entre os elementos do campo representacional á propósito de determinado objeto. ${ }^{16}$

A AFC avalia as correlações positivas e negativas existentes entre diferentes grupos e caracteres, colocando em evidência os campos semânticos definidos pelas palavras associadas ao estímulo e. destacando a contribuição para construção dos fatores ou eixos que constituem o plano fatorial. É ideal para explicar as representações obtidas através do teste de associação livre de palavras, o que enfoca as variáveis ativas ou de opiniões (em linha), que se confrontam e se revelam graficamente na representação do plano fatorial.

A Figura 1, que foi construída a partir desse processo, corresponde às representações ou adjetivos que os sujeitos evocaram a respeito do objeto em estudo, isto é, ao mapa dos agrupamentos e oposições entre os adjetivos associados à DST/ Aids. Apresenta, portanto, resultados que permitiram uma avaliação estatística dos dados no que concerne à freqüência (importância de contribuição das modalidades na construção dos fatores) e a representação gráfica das variáveis semânticas na definição do campo espacial.

Desse modo, configuraram-se graficamente as representações psicossociais relativas aos estímulos indutores, revelando-se aproximações e oposições das modalidades na construção dos fatores analisados através da AFC, definindo assim, ancoragem das gestantes sobre DST/Aids que fazem pré-natal, e tendo como referencial a TRS e o conceito de Moscovici.

\section{ANÁLISE DOS RESULTADOS}

Baseada na TRS, a realização deste estudo teve como elemento determinante as evocações das gestantes sobre DSTs / Aids que realizam prénatal no bairro satélite.

Destaca-se, assim, que a TRS é capaz de identificar vários aspectos psicológicos e sócio-culturais envolvidos na DST/Aids, considera o conhecimento das gestantes, revelando-se em um excelente instrumento na avaliação psicossocial que possibilitou a compreensão da DST/ Aids na ênfase dos aspectos psicológicos e sócio-culturais. 
Em relação às gestantes (sujeitos), a maioria encontrava-se na faixa etária de 20 a 30 anos e não tinham completado o ensino fundamental, 28 eram casadas, oito tinham união estável e quatro eram solteiras.

De acordo com as evocações das mulheres, surgiu um conjunto de 423 palavras como resposta para os estímulos indutores DST e DST/Aids, das quais 47 com significados diferentes. Esta redução obteve-se pela formação dos dicionários, através do agrupamento pela similaridade semântica existente entre as palavras, por exemplo, expressões como cuidado, prevenção, precaução, foram reduzidas a uma única palavra, cuidado, para se referir á DST.

Através da Figura 1, pode-se observar o conteúdo das representações sobre DST / Aids, tornandose possível a partir da objetivação configurada no campo representacional, fazer a leitura e interpretação das modalidades pelas palavras evocadas, correlacionando-as com as variáveis fixas (idade, estado civil e escolaridade) organizadas de maneira oposta, segundo os eixos ou Fatores (F1 e F2).

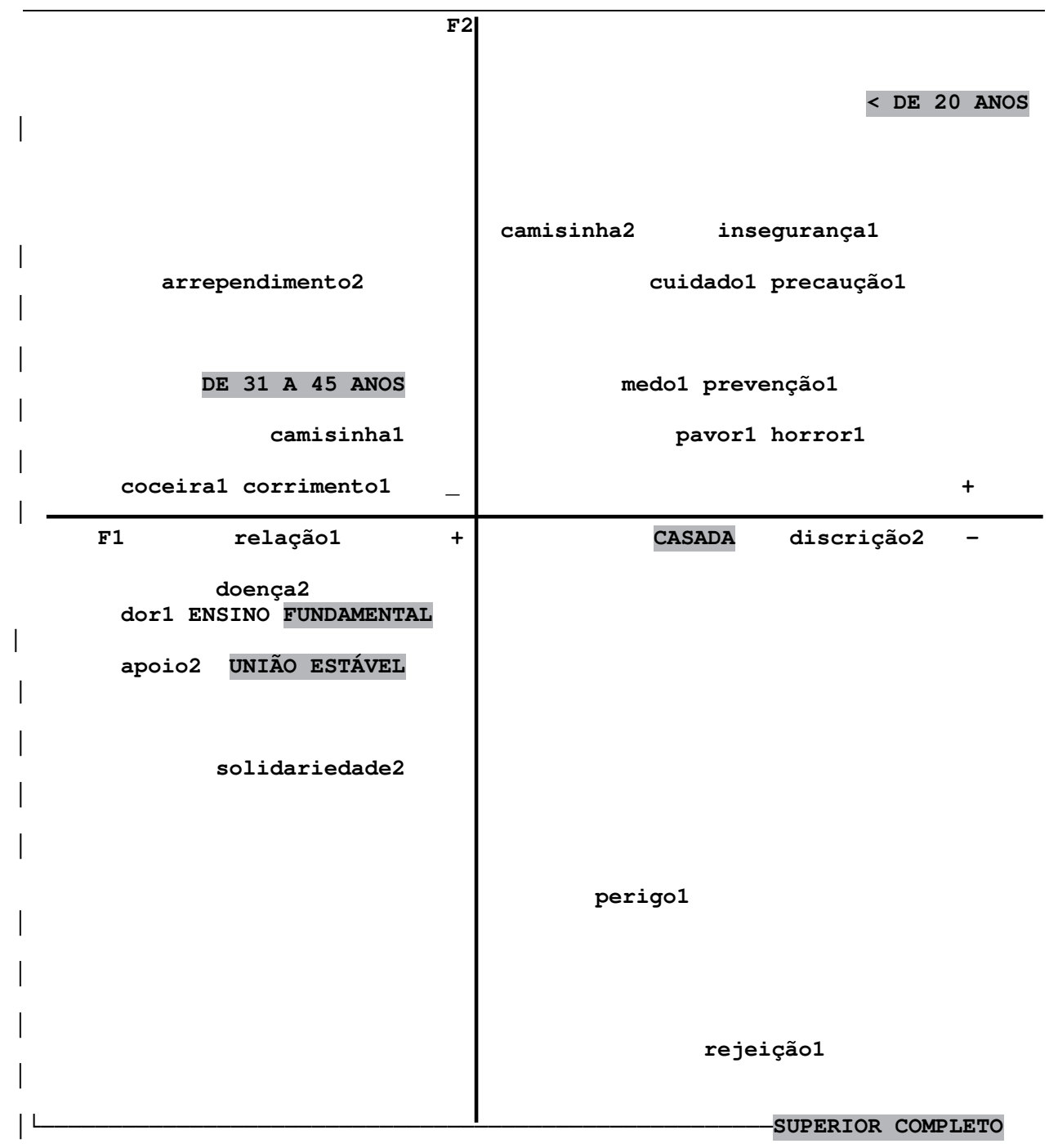

Legenda

\begin{tabular}{|c|c|c|}
\hline Plano fatorial & Palavras indutoras & Variáveis fixas \\
\hline $\begin{array}{l}\text { Fator } 1(\mathrm{~F} 1)=\text { [eixo horizontal - esquerdo } \\
\text { (negativo) e direito (positivo)] } \\
\text { Fator } 2(\mathrm{~F} 2)=\text { [eixo vertical - superior } \\
\text { (positivo) e (inferior negativo) }] \\
\text { Comum aos dois fatores - (F1-) } 2 \text { - DST / Aids e }(\mathrm{F} 1+) 1 \text { - DST }\end{array}$ & $\begin{array}{l}1 \text { - DST } \\
2 \text { - DST/Aids }\end{array}$ & $\begin{array}{l}\text { Idade } \\
\text { Estado civil } \\
\text { Escolaridade }\end{array}$ \\
\hline
\end{tabular}

Figura 1 - Representação gráfica do plano fatorial sobre DST/Aids na concepção das gestantes. Teresina-PI, 2006 
A Figura 1 resulta do cruzamento entre as variáveis fixas e as palavras evocadas, de acordo com as representações das gestantes sobre DST/ Aids que realizam pré-natal.

No F1, no lado esquerdo (negativo), o estimulo DST é contemplado pelas palavras camisinha, coceira, corrimento, relação e dor evocados por gestantes na faixa etária de 31 a 45 anos com ensino fundamental e união estável. Através dessas modalidades observa-se que as gestantes reconhecem a forma preventiva e identificam alguns sintomas que podem estar relacionados a complicações causadas pelas DSTs. No lado positivo, surgiram as palavras insegurança, cuidado, precaução, medo, prevenção, pavor e horror emitido por gestantes menores de 20 anos. Ainda no Fator 1 no lado negativo relativo ao estimulo DST/Aids surgem as palavras, arrependimento, doença e apoio evocadas por gestantes de 31 a 45 anos, com ensino fundamental e união estável e no lado positivo do mesmo fator, aparece a palavra discrição, expressada por mulheres casadas e menores de 20 anos.

No lado positivo do Fator F2 não houve representação gráfica como resposta ao estimulo DST e no lado negativo a palavra perigo foi evocada por gestantes com ensino superior completo. Quanto ao estimulo DST/Aids, no lado positivo aparece a palavra camisinha. A palavra camisinha, ancorada nos aspectos socioculturais diz respeito a importância da prevenção da DSTs com uso do preservativo, em relação a palavra perigo está ancorada no aspecto psicológico das gestantes com ensino superior completo o que demonstra conhecimento sobre o risco de adquirir as DSTs.

Comum aos dois fatores, encontra-se no lado negativo do Fator F1, como resposta ao estimulo DST/Aids, a palavra solidariedade e no lado positivo do mesmo eixo, surgiram apenas rejeição referente ao estimulo DST.

A solidariedade e rejeição são aspectos de cunho psicológico, ao mesmo tempo ter solidariedade é importante para quem se contamina com DST/Aids, no outro estímulo a rejeição preocupa as gestantes com DST.

Com relação às palavras pertinentes mais evocadas no campo representacional da representação social dos sujeitos, convém destacar a importância de conhecer os sintomas das DSTs que provocam sérias complicações, tais como infertilidade, abortamento espontâneo, malformações congênitas e até a morte, se não tratadas. ${ }^{1}$ Além disso, aumentam a chance, em pelo menos dez vezes, de contaminação pelo HIV. São doenças de difícil detecção, uma vez que acarretam poucos sintomas visíveis e, muitas vezes, apresentam-se de forma assintomática. ${ }^{7}$

Para se ter uma maior compreensão dos campos semânticos, apresenta-se na Tabela 1 as palavras mais evocadas pelas gestantes diante dos estímulos DST e DST/Aids que de acordo com os Fatores 1 e 2 foram: coceira, corrimento, dor, insegurança, medo, prevenção, perigo e camisinha, com bases nessas evocações, as gestantes evidenciam que os fatores que contribuem para DST estão relacionados a uma complicação no decorrer da gestação se não tratada.

Tabela 1 - Palavras evocadas diante dos estímulos indutores, que contribuíram para formação dos fatores 1 e 2. Teresina - PI, 2006

\begin{tabular}{lcr}
\hline Estímulos e palavras & \multicolumn{2}{c}{$\begin{array}{c}\text { Correspondência } \\
\text { por fator }\end{array}$} \\
& f & \% \\
\hline Estímulo 1 - DST & Fator $\mathbf{1}$ \\
Camisinha & 30 & 5,9 \\
Coceira & 67 & 13,3 \\
Corrimento & 59 & 17,7 \\
Cuidado & 45 & 8,9 \\
Dor & 62 & 12,3 \\
Insegurança & 38 & 7,5 \\
Medo & 78 & 15,5 \\
Prevenção & 92 & 18,3 \\
Relação & 31 & 6,1 \\
\hline Total & $\mathbf{5 0 2}$ & $\mathbf{1 0 0}$ \\
\hline Estímulo 2 - DST/Aids & Fator $\mathbf{2}$ & \\
Apoio & 57 & 24,6 \\
Arrependimento & 37 & 16 \\
Discrição & 104 & 45 \\
Doença & 33 & 14,2 \\
Solidariedade & 52 & 22,5 \\
\hline Total & $\mathbf{2 3 1}$ & $\mathbf{1 0 0}$ \\
\hline
\end{tabular}

As RSs enquanto teoria, práticas sobre determinado objeto ou problemas sociais específicos e importantes na vida dos grupos, alimentam e são produzidos numa interdependência do sujeito, objeto e interação social. Os fenômenos perceptivos, 
imagens, crenças ou atitudes que as representações sociais, somente adquirem estruturação lógica no entrelaçamento dos vínculos entre estes elementos, o que possibilita a atribuição de significados aos processos psicossociais. ${ }^{8}$

A partir daí é possível entender os aspectos psicossociais presentes nas culturas, nas manifestações, nos posicionamentos, nos sentimentos e nas evocações desses indivíduos, como integrantes sociais determinantes das medidas de prevenção e controle das DSTs e DST/Aids, tendo em vista que cooperam para orientação de condutas e organização do conhecimento em relação ao fenômeno social do estudo.

\section{CONSIDERAÇÕES FINAIS}

O presente estudo procurou apreender as representações sociais sobre DSTs e DST/Aids que se expressaram com aspectos sociais e culturais onde emergiram as evocações: camisinha, coceira, corrimento, prevenção, relação, dor, doença. Já os aspectos psicológicos foram ancorados nas palavras apoio, arrependimento, discrição, medo, pavor, horror, insegurança, cuidado, perigo, rejeição e solidariedade.

As DSTs e DST / Aids como objeto social constituiu o foco deste estudo, a partir do qual as gestantes puderam expressar as representações sociais através do instrumento de pesquisa, o teste de associação livre de palavras, possibilitando diferentes formas de se apreender às representações sociais.

Os resultados indicaram que o posicionamento frente às DSTs e DST/Aids é evidenciado com elementos favoráveis, tais como camisinha e prevenção. Isso mostra que a ênfase dada pelas gestantes ao reconhecimento do valor da proteção e prevenção responde aos apelos do seu grupo social e apóia-se no discurso dos profissionais da saúde, relacionado à importância de se prevenir contra DST como indispensável a uma boa condição de saúde.

As gestantes identificam palavras como coceira, corrimento e dor, associados às DSTs, ancorados em medo e prevenção psicologicamente elaborados, referente ao Fator 1 e estímulo 1. Já o estímulo 2 do mesmo Fator, as palavras mais evocadas foram discrição, arrependimento e apoio também de foco psicológico, ressaltando que as DSTs, são vistas com discrição para evitar discriminação, arrependimento talvez por não ter feito uso de medidas preventivas, aliado ao apoio.

Neste sentido, visualiza-se através do núcleo central das representações, que as gestantes estão cientes do conhecimento sobre a prevenção e o controle da DST e DST/Aids. Mas não podemos afirmar até que ponto esses conhecimentos estão sendo aplicados na vida cotidiana.

É necessário, pois ressaltar que a implementação dos programas de DST/ Aids, deve ser desenvolvido em consonância com as comunidades, sem desprezar o fato de que o grupo social contribui e exerce domínio na orientação de condutas. Sendo assim, o fato de existir diferença entre conhecimento científico e do senso comum não significa dizer que este último possa não ser perfeitamente válido para seus intentos, como meio de comunicação do conhecimento na vida cotidiana.

O estado atual das DSTs/Aids no país requer a implementação de um conjunto de ações de intervenção que possam reduzir seu impacto na população em geral e sobre os segmentos mais vulneráveis e, conseqüentemente, mais excluídos. Estas ações devem ser orientadas tomando os critérios de abrangência populacional, epidemiológico e de focalização, priorizando aquelas dirigidas para as populações de risco e, portanto, mais vulneráveis. E no caso das gestantes ainda consta mais um agravante, que é a possibilidade de transmitir verticalmente alguma DST ao seu concepto, caso não sejam adotados medidas preventivas.

\section{REFERÊNCIAS}

1. Fernandes MAS, Antonio DG, Bahamondes LG, Cupertino CV. Conhecimento, atitudes e práticas de mulheres brasileiras atendidas pela rede básica de saúde com relação às doenças de transmissão sexual. Cad Saúde Pública. 2000 Jan-Mar; 16(Supl 1):103-12.

2. Ministério da Saúde (BR). Manual de controle das doenças sexualmente transmissíveis. L - AIDS. Brasília (DF): MS; 2001/2002. p.5-9.

3. Ministério da Saúde (BR). Manual de Controle das doenças sexualmente transmissíveis. Brasília (DF): MS; 2006.

4. Ayres JRCM, Calazans GJ, França JR. AIDS, vulnerabilidade e prevenção. In: Seminário saúde reprodutiva em tempos de AIDS; Nov 7-9; Rio de Janeiro (RJ): ABIA; 1997. p. 20-37.

5. Parker R. Na contramão da AIDS: sexualidade, intervenção e política. Rio de Janeiro (RJ): ABIA; 2000.

6. Figueiredo RMD. Repensando estereótipos e a mulher frenteás DST e AIDS para ações de saúde. In: Prevenção ás DST e AIDS em ações de saúde e educação. São Paulo (SP): NepAids/USP; 1998. p. 23-5.

7. Ministério da Saúde (BR). Assistência ao Pré-Natal e Puerpério - Assistência qualificada e humanizada. Brasília (DF): MS, 2005. 
8. Jodelet D. As Representações Sociais. Rio de Janeiro (RJ): UERJ; 2001.

9. Nóbrega SM, Coutinho MPL. O Teste de Associação Livre de Palavras. In: Representações Sociais: Abordagem Interdisciplinar. João Pessoa (PB): Universitária da UFPB; 2003.

10. Jovechlovitch S. Representações sociais e esfera pública: a construção simbólica dos espaços públicos do Brasil. Petrópolis (RJ): Vozes; 2000.

11. Sá CP. A Construção do objeto de pesquisa em Representações Sociais. Rio de Janeiro (RJ): EDUERJ; 1998.
12. Columbrini MRC, Mucke AG, Figueiredo RM. Enfermagem em infectologia: Cuidados com o paciente internado. São Paulo (SP): Atheneu; 2000.

13. Moscovici S. A representação social da psicanálise. Rio de Janeiro (RJ): Zahar; 1978.

14. Chizzotti A. Pesquisa em Ciências Humanas e Sociais. São Paulo (SP): Cortez; 1998.

15. Gil AC. Método e técnicas de pesquisa social. $5^{\mathrm{a}} \mathrm{ed}$. São Paulo (SP): Atlas; 2002.

16. Coutinho MPL, Lima AS, Oliveira FB, Fortunato Ml. Representações Sociais: abordagem interdisciplinar. João Pessoa (PB): Universitária da UFPB; 2003. 